\title{
Anaemia in term pregnancy: influence on maternal and perinatal outcome and role of demographic factors
}

\author{
Urvashi Miglani, Priya Bhangadia*, V. K. Kadam, Poonam Laul
}

Department of Obstetrics and Gynecology, Deen Dayal Upadhyay Hospital, New Delhi, Delhi, India

Received: 18 October 2018

Accepted: 13 December 2018

\section{*Correspondence:}

Dr. Priya Bhangadia,

E-mail: bhangadiapriya@gmail.com

Copyright: (C) the author(s), publisher and licensee Medip Academy. This is an open-access article distributed under the terms of the Creative Commons Attribution Non-Commercial License, which permits unrestricted non-commercial use, distribution, and reproduction in any medium, provided the original work is properly cited.

\begin{abstract}
Background: The aim is to study maternal and perinatal outcome and various demographic factors in term pregnancy complicated with anaemia at DDU Hospital.

Methods: Hospital based prospective observational analytical study. 200 pregnant women reporting to antenatal clinic or admitted to the Hospital in labour/not in labour after 36+6weeks of pregnancy were taken as study subjects. Study duration was one year between July 2017 to June 2018.

Results: The prevalence of mild, moderate and severe anaemia was $25 \%, 56 \%$ and $19 \%$ respectively. Education status, socioeconomic status, ANC visit, interpregnancy interval were significantly associated with anemia $(\mathrm{p}<0.05)$. Significant association was observed between occurrence of PPH and severity of anaemia(OR 12.77; CI 2.32 to 70.12). The incidence of LBW increased with severity of anaemia. (OR-6.25;CI 2.6 to 15). There was a statistically significant difference found in prevalence of IUGR babies. The risk of Apgar score $<8$ increased with severity of anaemia. Perinatal mortality was observed in $8 \%$ subjects with anaemia as compared to $3 \%$ in subjects without anaemia.

Conclusions: Maternal anaemia is a major public health problem. Simple steps taken to correct anaemia in female contemplating pregnancy and pregnant women can definitely have far reaching influences on maternal and perinatal morbidity.
\end{abstract}

Keywords: Anemia, Demographic factors, Perinatal outcome

\section{INTRODUCTION}

Anaemia is a major public health problem throughout the world specially in developing countries like India and it is the most common nutritional deficiency disorder in the world. ${ }^{1}$ High prevalence of anaemia among pregnant women persists in India despite the availability of effective and low-cost interventions for prevention and treatment.

World Health Organization (WHO) has estimated the prevalence of anaemia among pregnant population to be about $38 \% .^{2}$ Iron deficiency anaemia (IDA) is the most common and primary cause of anaemia. The prevalence of anaemia indicates the nutritional status of a community and it often goes untreated especially in pregnant women where it can be most dangerous. ${ }^{3}$

Iron deficiency anaemia is an important public health problem for pregnant women, living in developing countries, affecting $2 / 3^{\text {rd }}$ of pregnant women and contributes to maternal morbidity and mortality and to low birth weight. ${ }^{4,5}$ Socio-economic deprivation which has been linked with the development, severity and outcome of many medical conditions is an overlooked factor. In addition, lack of education and understanding 
about health-related issues can contribute to delays in seeking care when it is needed or to the inappropriate management of life-threatening pregnancy complications.

In tropical countries, deficiency of both iron and folic acid deficiency which is seen is directly associated with poor health status, poverty, poor socioeconomic status, multiparity and less birth spacing. ${ }^{1}$

Anaemia has hazardous influence on maternal and fetal outcome and increases risk of postpartum haemorrhage $(\mathrm{PPH})$, infection, sepsis and risk for pre-term birth, low birth weight and small for gestational age babies thereby contributing to maternal and perinatal morbidity and sometimes mortality. ${ }^{6}$

Considering the effects of IDA on maternal and fetal mortalities, physical function and child growth and development, it is regarded as one of the main health indicators. ${ }^{3}$ In fact the high incidence of post-partum haemorrhage (PPH) in India as compared to rest of world has been attributed to the high prevalence of anaemia in pregnant women. ${ }^{2}$

In view of the above-mentioned adverse effects of anaemia in pregnancy this study was planned in our hospital to evaluate the fetomaternal outcome due to anaemia in pregnancy and to also explore the potential role of demographic factors.

\section{METHODS}

This was a hospital based prospective observational analytical study conducted in Department of obstetrics and Gynaecology at Deen Dayal Upadhyay Hospital, New Delhi. 200 pregnant women reporting to antenatal clinic or admitted to the Hospital in labour/not in labour after $36+6$ weeks of pregnancy were taken as study subjects. Study duration was one year from July 2017 to June 2018.

\section{Exclusion criteria}

- Patients with anaemia due to acute blood loss.

The study protocol was approved by the Ethics committee board of DDU Hospital. After written and informed consent, a detailed history was taken from all study subjects with reference to age, literacy, booking status ( $\geq 3$ visits as booked), socioeconomic status (according to B. G. Prasad classification), detailed obstetric and menstrual history, past surgical and medical history, history of blood transfusion, interpregnancy interval and chronic medical illness.

All the routine haematological and biochemical investigations were carried out .

- Complete haemogram and peripheral blood smear
- Urine routine examination and microscopy and culture sensitivity.

- $\quad$ Serum Iron/Folate/ferritin in selected patients

- Ultrasound for fetal well being

- $\quad$ Any other investigations as and when required.

They were induced as per the obstetric indications. Incidence of intrapartum, postpartum and perinatal complications was studied.

\section{Statistical analysis}

Statistical testing was conducted with the statistical package for the social science system version (SPSS) 17.0. Continuous variables were presented as mean \pm SD or median (IQR) for non-normally distributed data. Categorical variables were expressed as frequencies and percentages. The comparison of normally distributed continuous variables between the groups was performed using Student's t test. Nominal categorical data between the groups was compared using Chi-square test or Fisher's exact test as appropriate. Non-normal distribution continuous variables were compared using Mann Whitney $U$ test. For all statistical tests, a p value less than 0.05 was taken to indicate a significant difference.

\section{RESULTS}

In the present study 100 subjects with anaemia have been compared to 100 subjects without anaemia to evaluate role of sociodemographic factors, other contributing illness and to study the influence of anaemia on fetomaternal outcome. In the present study, the prevalence of mild, moderate and severe anaemia was $25 \%, 56 \%$ and $19 \%$ respectively. The proportion of pregnant women with or without anaemia was more in the age group of 26-30 years, $45 \%$ in subjects with anaemia and $40 \%$ in subjects without anaemia.

However, this was not statistically significant possibly due to small sample size. $40 \%$ of subjects with anaemia belong to class IV and $21 \%$ belong to class $\mathrm{V}$ and rest $6 \%, 9 \%$ and $24 \%$ to class I, II and class III respectively. In contrast among non-anaemics, $21 \%$ belong to class I, $40 \%$ to class II, $20 \%$ to class III, $14 \%$ and $5 \%$ to class IV and class $\mathrm{V}$ respectively and this difference was statistically significant in both the groups.

$47 \%$ of subjects with anaemia were illiterate as compared to $15 \%$ subjects without anaemia and only fewer subjects with anaemia have done graduation as compared to other group (9\% vs. 36\%) and this difference was statistically significant $(\mathrm{p}<0.05) .65 \%$ subjects with anaemia were unbooked as compared to $40 \%$ subjects without anaemia. ( $\mathrm{p}<0.05$ ). $40 \%$ subjects with anaemia were nulliparous as compared to $56 \%$ subjects without anaemia; $60 \%$ subjects with anaemia were multiparous as compared to $44 \%$ subjects without anaemia $(\mathrm{p}<0.05)$ (Table 1$)$. 
Table 1: demographics of study population.

\begin{tabular}{|c|c|c|c|}
\hline Demographic factors & Subjects with anaemia( $(n=100)$ & Subjects without anaemia $(\mathrm{n}=100)$ & P value \\
\hline \multicolumn{4}{|l|}{ Age } \\
\hline$\leq 20$ years & $11(11 \%)$ & $11(11 \%)$ & \multirow{4}{*}{$\begin{array}{l}0.76 \\
\text { (not significant) }\end{array}$} \\
\hline $21-25$ years & $34(34 \%)$ & $41(41 \%)$ & \\
\hline $26-30$ years & $45(45 \%)$ & $40(40 \%)$ & \\
\hline$>30$ years & $10(10 \%)$ & $8(8 \%)$ & \\
\hline \multicolumn{4}{|l|}{ Socioeconomic class } \\
\hline I & $6(6 \%)$ & $21(21 \%)$ & \multirow{5}{*}{$\begin{array}{l}<0.05 \\
\text { (significant) }\end{array}$} \\
\hline II & $9(9 \%)$ & $40(40 \%)$ & \\
\hline III & $24(24 \%)$ & $20(20 \%)$ & \\
\hline IV & $40(40 \%)$ & $14(14 \%)$ & \\
\hline V & $21(21 \%)$ & $5(5 \%)$ & \\
\hline \multicolumn{4}{|l|}{ Education level } \\
\hline Illiterate & $47(47 \%)$ & $15(15 \%)$ & \multirow{3}{*}{$\begin{array}{l}<0.05 \\
\text { (significant) }\end{array}$} \\
\hline School level & $44(44 \%)$ & $49(49 \%)$ & \\
\hline Graduate & $9(9 \%)$ & $36(36 \%)$ & \\
\hline \multicolumn{4}{|l|}{ Booking status } \\
\hline Booked & $35(35 \%)$ & $60(60 \%)$ & \multirow{2}{*}{$\begin{array}{l}<0.05 \\
\text { (significant) }\end{array}$} \\
\hline Unbooked & $65(65 \%)$ & $40(40 \%)$ & \\
\hline \multicolumn{4}{|l|}{ Parity } \\
\hline Nulliparous & $40(40 \%)$ & $56(56 \%)$ & \multirow{2}{*}{$\begin{array}{l}<0.05 \\
\text { (significant) }\end{array}$} \\
\hline Multiparous & $60(60 \%)$ & $44(44 \%)$ & \\
\hline Interpregnancy interval & Anaemia $(n *=65)$ & Non-anaemia $(n *=49)$ & \multirow{3}{*}{$\begin{array}{l}<0.05 \\
\text { (significant) }\end{array}$} \\
\hline$\leq 2$ years & $36(55.38 \%)$ & $16(32.65 \%)$ & \\
\hline$>2$ years & $29(44.62 \%)$ & $33(67.35 \%)$ & \\
\hline
\end{tabular}

$\mathrm{n} *=$ number of multigravida women among subjects with anemia and subjects without anemia.

$55.38 \%$ subjects with anaemia had interpregnancy interval of $\leq 2$ years in comparison with $32.65 \%$ subjects without anaemia. $(\mathrm{p}<0.05)$. Statistically significant association was found between preeclampsia and anaemia, $(21 \%$ vs. $10 \%)$ as well as between parasitic infection and anaemia (8\% v/s $0 \%)$. Occurrence of anaemia in subjects with urinary tract infection was $3 \%$ more $(7 \% \mathrm{v} / \mathrm{s} 4 \%)$ (Table 2$)$.

Table 2: Comparison of anaemia and medical illness in subjects.

\begin{tabular}{|l|l|l|l|}
\hline Medical illness & Anaemia & $\begin{array}{l}\text { Non- } \\
\text { anaemia }\end{array}$ & P value \\
\hline Pre-eclampsia & $21(21 \%)$ & $10(10 \%)$ & $\begin{array}{l}0.03 \\
\text { (significant) }\end{array}$ \\
\hline UTI & $7(7 \%)$ & $4(4 \%)$ & $\begin{array}{l}0.35 \text { (not } \\
\text { significant) }\end{array}$ \\
\hline $\begin{array}{l}\text { Hookworm/round } \\
\text {-worm infections }\end{array}$ & $8(8 \%)$ & 0 & $\begin{array}{l}0.003 \\
\text { (significant) }\end{array}$ \\
\hline
\end{tabular}

5\% subjects with anaemia had cardiac failure due to severe anaemia and $17 \%$ subjects had puerperal sepsis while only $2 \%$ subjects without anaemia had puerperal sepsis. 26\% subjects with anaemia had postpartum haemorrhage (PPH) as compared to $4 \%$ subjects without anaemia (Table 3). Significant association was observed between occurrence of PPH and severity of anaemia.
Severely anaemic subjects had high incidence of PPH (Table 4).

Table 3: Comparison of maternal complications between subjects with anemia and subjects without anemia.

\begin{tabular}{|l|l|l|l|}
\hline Complications & $\begin{array}{l}\text { Subjects } \\
\text { with } \\
\text { anemia } \\
(\mathbf{n = 1 0 0 )}\end{array}$ & $\begin{array}{l}\text { Subjects } \\
\text { without } \\
\text { anemia } \\
(\mathbf{n = 1 0 0 )}\end{array}$ & P value \\
\hline Cardiac failure & $5(5 \%)$ & 0 & $\begin{array}{l}0.02 \\
\text { (significant) }\end{array}$ \\
\hline $\begin{array}{l}\text { Puerperal sepsis } \\
\text { (wound infections/ } \\
\text { retained placenta) }\end{array}$ & $17(17 \%)$ & $2(2 \%)$ & $\begin{array}{l}0.0003 \\
\text { (significant) }\end{array}$ \\
\hline PPH & $26(26 \%)$ & $4(4 \%)$ & $\begin{array}{l}<0.05 \\
\text { (significant) }\end{array}$ \\
\hline
\end{tabular}

$8.6 \%$ babies of subjects with anaemia had birth asphyxia v/s. $2.06 \%$ in subjects without anaemia. $13.9 \%$ babies of anaemic mothers had Respiratory distress syndrome v/s $5.1 \%$ among non-anaemic (statistically significant).

Occurrence of Meconium aspiration syndrome was $5.44 \%$ more in subjects with anaemia than in the subjects without an occurrence of other complications like jaundice was $4.34 \%$ more in subjects with anaemia than 
in the subjects without anaemia $(6.4 \% \mathrm{v} / \mathrm{s} 2.06 \%)$ (Table 5).

The incidence of low birth weight $\mathrm{LBW}(<2.5 \mathrm{~kg})$ was significantly high $(32 \%)$ in subjects with anaemia as compared to subjects without anaemia (7\%).

The incidence of LBW increased with severity of anaemia. (OR-6.25; CI 2.6 to 15) (Table 6).
Table 4: Comparison of severity of anaemia and PPH.

\begin{tabular}{|l|l|l|l|l|}
\hline & $\begin{array}{l}\text { PPH } \\
\text { present }\end{array}$ & \multicolumn{1}{|l|}{$\begin{array}{l}\text { PPH } \\
\text { absent }\end{array}$} & $\chi^{2}$ & P value \\
\hline $\begin{array}{l}\text { Mild anaemia } \\
(\mathrm{n}=25)\end{array}$ & 2 & 23 & 3.15 & $0.07 *$ \\
\hline $\begin{array}{l}\text { Moderate } \\
\text { anaemia (n=56) }\end{array}$ & 14 & 42 & 4.97 & $0.02 * *$ \\
\hline $\begin{array}{l}\text { Severe anaemia } \\
(\mathrm{n}=19)\end{array}$ & 10 & 9 & 10.84 & $0.001 * *$ \\
\hline
\end{tabular}

Table 5: Comparison of perinatal complications between subjects with anemia and subjects without anemia.

\begin{tabular}{|l|l|l|l|}
\hline Complications & Subjects with anemia $(\mathbf{n = 9 2})$ & Subjects without anemia $(\mathbf{n}=97 \%)$ & P value \\
\hline Birth asphyxia & $8(8.6 \%)$ & $2(2.06 \%)$ & 0.04 (significant) \\
\hline RDS & $13(13.9 \%)$ & $5(5.1 \%)$ & 0.03 (significant) \\
\hline Mas & $7(7.5 \%)$ & $2(2.06 \%)$ & 0.07 (not significant) \\
\hline Others & $6(6.4 \%)$ & $2(2.06 \%)$ & 0.13 (not significant) \\
\hline
\end{tabular}

*8 deaths in subjects with anaemia and 3 deaths in subjects without anaemia

There is a statistically significant difference found in prevalence of IUGR babies, $12 \%$ vs. $2 \%$ in subjects with anaemia and without anaemia respectively and also between mildly and severely anaemic subjects (Table 6).
$13 \%$ babies of subjects with anaemia had Apgar score $<8$ at 1 minute which was significantly higher than in subjects without anaemia $(4.12 \%)$.

Table 6: Comparison of perinatal outcome among subjects with anaemia and without anaemia.

\begin{tabular}{|c|c|c|c|c|c|}
\hline \multirow[b]{2}{*}{ Perinatal outcome } & \multicolumn{3}{|c|}{ Anaemia $(n=100)$} & \multirow[b]{2}{*}{$\begin{array}{l}\text { Non-anaemia } \\
(n=100)\end{array}$} & \multirow[b]{2}{*}{ P value } \\
\hline & $\begin{array}{l}\text { Mild } \\
(n=25)\end{array}$ & $\begin{array}{l}\text { Moderate } \\
(\mathrm{n}=56)\end{array}$ & $\begin{array}{l}\text { Severe } \\
(n=19)\end{array}$ & & \\
\hline Low birth weight $(<2.5 \mathrm{~kg})$ & $1(4 \%)$ & $16(28.5 \%)$ & $15(78.94 \%)$ & $7(7 \%)$ & $<0.05$ (significant) \\
\hline IUGR present & $1(4 \%)$ & $4(7.14 \%)$ & $7(36.84 \%)$ & $2(2 \%)$ & $<0.05$ (significant) \\
\hline \multirow{3}{*}{ Apgar $<8$} & \multicolumn{3}{|c|}{ Anaemia $(n *=92)$} & \multirow{2}{*}{ Non-anaemia $(n *=97)$} & \multirow{3}{*}{$<0.05$ (significant) } \\
\hline & Mild & Moderate & Severe & & \\
\hline & $1(4 \%)$ & $7(13.2 \%)$ & $4(28.57 \%)$ & $4(4.12 \%)$ & \\
\hline
\end{tabular}

Subjects with anaemia had 3-fold higher risk of low Apgar score as compared to subjects without anaemia (OR-3.48).

Table 7: Showing NICU admission among study subjects.

\begin{tabular}{|c|c|c|c|}
\hline & $\begin{array}{l}\text { Anaemia } \\
(n *=92)\end{array}$ & $\begin{array}{l}\text { Non-anaemia } \\
\left(n^{*}=97\right)\end{array}$ & P value \\
\hline $\begin{array}{l}\text { NICU } \\
\text { admission }\end{array}$ & $33(35.86 \%)$ & $12(12.37 \%)$ & $\begin{array}{l}<0.05 \\
\text { (significant) }\end{array}$ \\
\hline
\end{tabular}

The risk of Apgar score $<8$ increases with severity of anaemia (Table 6). $35.86 \%$ babies of anaemic subjects were admitted to NICU as compared to $12.37 \%$ subjects without anaemia. Difference was statistically significant (Table 7).

\section{DISCUSSION}

Anaemia in pregnancy is a worldwide phenomenon but particularly more prevalent and severe in the developing countries. ${ }^{6}$ In India, there is high prevalence of anaemia among non-pregnant population and they start pregnancy in anaemic state which is further aggravated by increased requirements of pregnancy and blood loss at delivery. Infections in the antenatal and postnatal periods and early advent of next pregnancy perpetuate it. Maternal anaemia has been found to be associated with higher maternal mortality and morbidity and adverse perinatal outcome. ${ }^{7,8}$ 
In the present study, the prevalence of mild, moderate and severe anaemia was $25 \%, 56 \%$ and $19 \%$ respectively. According to National Family Health Survey NFHS-4 (2015-16), the prevalence of anaemia among pregnant women is $50.3 \%$; the prevalence of mild anaemia and moderate anaemia is about $24.5 \%$ each and of severe anaemia around $1.3 \%$.

The high prevalence of severe anaemia in the present study is probably attributed due to the high proportion of referred cases as our institute is the only tertiary care centre in west Delhi.

Older pregnant women have a higher burden of anaemia than younger ones. This might be due to the cumulative effect of the repeated pregnancies, persistent inadequate diet, similar environmental and social factors which drain on the maternal health and lead to anaemia in pregnancy. In the present study, the proportion of pregnant women with or without anaemia was more in the age group of 26-30 years.

Khan NAM et al in their study found a statistically significant association between age and prevalence of anaemia. The proportion of the pregnant women suffering from anaemia were maximum $(96.55 \%)$ in the age group 30 years or above and minimum $(79.8 \%)$ were in the 20 24 age group 9 .

Low socioeconomic status is a risk factor for anaemia possibly due to the associated poor nutrition, lack of access to healthcare facilities, low level of income and low level of education. There was statistically significant difference observed in socioeconomic status of both the groups. Majority of subjects belonged to class IV in anaemic (40\%) as compared to $14 \%$ among non anaemic. Bedi $\mathrm{R}$ et al also observed the same in their study, $50.26 \%$ among socio-economic status IV and V women were significantly more anaemic as compared to non anaemic group. ${ }^{10}$ This association can probably be explained by numerous contributing factors like poor nutrition, logistic and financial constraints, hesitation in approaching healthcare facilities being some of them.

Educational status has for long been conventionally linked with anaemia, the lower the education level of women, the higher probability of suffering from anaemia during pregnancy as was also reflected in the present study. Malhotra P et al also observed that prevalence of anaemia was $51.3 \%$ amongst illiterate women as compared to $43.5 \%$ prevalence in educated women. ${ }^{11}$

Regular antenatal checkups and adequate care is the cornerstone for safe motherhood. In the present study, significantly higher number of subjects with anaemia was unbooked as compared to subjects without anaemia $(65 \%$ vs. $40 \%$ ) respectively. Similarly, Bedi R et al observed that the mother who had $<3$ antenatal visits were significantly more anaemic in his study. ${ }^{10}$ It is obvious that booked cases receive regular and supervised care during pregnancy where complications are diagnosed early and treated appropriately. Anaemia in pregnancy is more common in women of high parity (as shown in the present study) due to repeated pregnancy and inadequate spacing. ${ }^{12}$ Malhotra $\mathrm{M}$ et al also found that women with parity $>3$ were severely anaemic as compared to other groups. ${ }^{13}$

Significantly higher number of women with anaemia had birth spacing less than 2 years. Kozuki $\mathrm{N}$ et al studied that birth intervals shorter than 18 months are significantly associated with SGA, preterm birth and death in the first year of life14.The susceptibility of women with severe anaemia to preeclampsia could be explained by a deficiency of micronutrients and antioxidants. In the present study $21 \%$ of subjects with anaemia had associated pre-eclampsia as compared to $10 \%$ subjects without anaemia and the difference found to be statistically significant. Ali AA et al also found the prevalence of preeclampsia and eclampsia was significantly higher in women with severe anaemia. ${ }^{15}$ In the present study, 7\% subjects with anaemia had associated urinary tract infection as compared to $4 \%$ subjects without anaemia but the difference is statistically not significant. The exact mechanism behind association of anaemia and UTI is unknown. Refractory anaemia appears in the course of advanced chronic pyelonephritis which causes decrease in the secretion of erythropoietin. In anaemia of chronic disease, possibly infection results in disturbed metabolism of iron and decrease absorption. Giles $\mathrm{C}$ et al in their study observed that Urinary infection was more than twice as common in the anaemic patients as in the controls. ${ }^{16}$

Parasitic diseases like hookworm, roundworm and malaria cause iron deficiency anaemia through the process of intestinal blood loss and through nitric oxide (NO) release and can exacerbate anaemia and adverse birth outcomes. ${ }^{17,18}$ This is also corroborated in the present study .Getachew $\mathrm{M}$ et al found significant correlation between increasing hookworm parasite load and decreasing haematocrit value. ${ }^{19}$ Anaemia of pregnancy is an important contributor to maternal mortality and morbidity in developing countries (WHO 1993). Maternal effects of anaemia vary, depending upon the degree of anaemia. It can directly lead to cardiac failure, haemorrhage and infection. Severe anaemia may impair myometrial contractility resulting from impaired oxygen carrying capacity leading to enzyme and cellular dysfunction which leads to postpartum haemorrhage $(\mathrm{PPH}){ }^{20}$ Presence of anaemia in pregnancy was significantly associated with occurrence of cardiac failure, puerperal sepsis and PPH in present study and significant association was also observed between occurrence of PPH and severity of anaemia. Subjects with anaemia had eightfold higher odds of PPH as compared to non anaemic (OR $8.43 ; 95 \%$ CI 2.81 to 25.21) (Table 3). The odds of PPH were 12-fold higher in subjects with severe anaemia as compared to mild anaemia(OR 12.77; CI 2.32 to 70.12).(TABLE 
NO.3.1.1). In a study done by Nair $M$ et al they found nine-fold higher odds of PPH in severe anaemia. The higher odd in the present study is probably due to higher prevalence of severe anaemia. ${ }^{21}$

Anaemia in pregnancy is associated with adverse foetal outcome in the form of preterm birth, low birth weight, intrauterine growth restriction, stillbirths, intrauterine foetal death, and birth asphyxia. The birth weight of baby may be dependent on maternal haemoglobin concentration, since it is required for oxygen transport across the placenta and the oxygen supply may have a direct bearing on the development of IUGR. As observed above birth asphyxia and RDS were significantly associated with presence of anaemia. Sangeeta VB et al concluded that there was 1.6 times increased risk of birth asphyxia among anaemic subjects. ${ }^{22}$ Kiyani AN et al in their study on 196 newborns, observed that maternal anaemia was seen in $58 \%$ cases of birth asphyxia at the time of delivery. ${ }^{23}$

In the present study the incidence of low birth weight $(<2.5 \mathrm{~kg})$ was found to be significantly associated with presence of anaemia .In the present study, the risk of having LBW babies in subjects with anaemia was 6 times higher than in subjects without anaemia(OR-6.25;CI 2.6 to 15$)$. Sangeeta VB et al observed 2.5 times increased risk of LBW among anaemic cases. ${ }^{22}$ Risk of having low APGAR was associated with presence of anemia and risk increased with severity in the study. Subjects with anaemia had 3-fold higher risk of low Apgar score. In a study done by Rani KU et al, Apgar score <7 at 5 minutes was significantly more in severe anaemic as compared to mild to moderate anaemic $(41.71 \%$ vs. $24.86 \%){ }^{24}$

The prevalence of IUGR was higher in anaemic women and increases with the severity of anaemia. A metanalysis was conducted by Kozuki $\mathrm{N}$ et al on studies reporting association between maternal anaemia and SGA, there were 7 associations with a haemoglobin cut off $<110 \mathrm{~g} / \mathrm{L}$, 7 with a cut-off $<100 \mathrm{~g} / \mathrm{L}$, and 5 with a cut-off $<90$ or $<80 \mathrm{~g} / \mathrm{L}$. They revealed a close to $50 \%$ increase in odds of Small for gestational age (SGA) for mothers with moderate to severe anaemia than mild anaemia. ${ }^{12,14}$

In the present study admission rate to NICU was more in babies of subjects with anaemia than without anaemia. Makka SS et al in their study on 100 pregnant women, found $25 \%$ babies of subjects with anaemia were admitted to NICU as compared to non anaemics. ${ }^{25}$ Total three maternal deaths were observed in subjects with anaemia and perinatal mortality was observed in $8 \%$ subjects with anaemia as compared to $3 \%$ in subjects without anaemia.

\section{CONCLUSION}

Anaemia has severe hazardous influence on fetomaternal outcome and simple steps taken to correct anaemia in female contemplating pregnancy and pregnant women can definitely have far reaching influences on maternal and perinatal morbidity.

Funding: No funding sources

Conflict of interest: None declared

Ethical approval: The study was approved by the Institutional Ethics Committee

\section{REFERENCES}

1. Kaur K. Anaemia 'a silent killer 'among women in India: Present scenario. European Journal of Zoological Res. 2014;3(1):32-6.

2. The global prevalence of anaemia in 2011. World Health Organization;[Online] 2015. Available Online from appswho.int/iris/bitstream/10665/177094/1/ 9789241564960_eng.pdf.

3. Panghal R, Boora P. Prevalence of anaemia among pregnant women of low-income group of Hisar district of Haryana. J Dairying, Foods Home Sci. 2010;29(2):112-5.

4. Pasricha SR, Caruana SR, Phuc TQ, Casey GJ, Jolley D, Kingsland S, et al. Anemia, iron deficiency, meat consumption, and hookworm infection in women of reproductive age in northwest Vietnam. Am J Trop Medicine and Hygiene. 2008;78(3):37581.

5. Baig-Ansari N, Badruddin SH, Karmaliani R, Harris $\mathrm{H}$, Jehan I, Pasha O, Moss N, McClure EM, Goldenberg RL. Anemia prevalence and risk factors in pregnant women in an urban area of Pakistan. Food Nutri Bulletin. 2008;29(2):132-9.

6. Diejomaeoh FME, Abdulaziz A, Adekile AD. Anemia in pregnancy. Int $\mathrm{J}$ ObstetGynecol 1999;65(3):299-301.

7. Bhatt R. Maternal mortality in India FOGSI-WHO study. J Obstet Gynecol Ind. 1997;47:207-14.

8. Reddy V, Rao NP, Sastry JG, Kashinath K. Nutritional trends in India. Hyderabad National Institute of Nutrition, 1993.

9. Khan NA, Sonkar VR, Domple VK, Inamdar IA. Study of Anaemia and Its Associated Risk Factors among Pregnant Women in a Rural Field Practice Area Medical College. Community Med. 2017; 8(7):396-400.

10. Bedi R, Acharya R, Gupta R, Pawar S, Sharma R. Maternal factors of anemia in 3rd trimester of Pregnancy and its association with fetal outcome. Int Multispecialty J Health (IMJH). 2015;1(7):9.

11. Malhotra P, Kumari S, Kumar R, Varma S. Prevalence of anaemia in adult rural population of north India. J Assoc Physicians India. 2004;52:1820.

12. Konar H. DC Dutta's Textbook of Obstetrics. JP Medical Ltd; 2014.

13. Malhotra M, Sharma JB, Batra S, Sharma S, Murthy NS, Arora R. Maternal and perinatal outcome in varying degrees of anaemia. Int $\mathbf{J}$ Gynaecol Obstet. 2002;79(2):93-100. 
14. Kozuki N, Lee AC, Silveira MF, Victora CG, Adair L, Humphrey J, Ntozini R, Black RE, Katz J. The associations of birth intervals with small-forgestational-age, preterm, and neonatal and infant mortality: a meta-analysis. BMC Pub Health. 2013;13(3):S3.

15. Ali AA, Rayis DA, Abdallah TM, Elbashir MI, Adam I. Severe anaemia is associated with a higher risk for preeclampsia and poor perinatal outcomes in Kassala hospital, eastern Sudan. BMC Res Notes. 2011;4(1):311.

16. Giles C, Brown JA. Urinary infection and anaemia in pregnancy. BMJ. 1962;2(5296):10-3.

17. Gilles HM, Williams EJ, Ball PA: Hookworm infection and anaemia.An epidemiological, clinical, and laboratory Study. Q J Med. 1964;33:1-24.

18. Nelly JY, Jiang YI, Tsiri A: Malaria and Intestinal Helminth Co-Infection Among Pregnant Women in Ghana: Prevalence and Risk Factors. Am J Trop Med Hyg. 2009;80(6):896-901.

19. Getachew M, Yewhalaw D, Tafess K, Getachew Y, Zeynudin A. Anaemia and associated risk factors among pregnant women in Gilgel Gibe dam area, Southwest Ethiopia. Parasites and Vect. 2012; 5(1):296.

20. Tusimin M, Yazit A, Zainulddin NS, Vaiappuri VSSKN, Md Noor S (2016) The Impact of Severity of Antenatal Anaemia on Maternal and Perinatal Outcome in Hospital Serdang, Central Malaysia. J Preg Child Health. 2016 3:291.
21. Nair M, Choudhury MK, Choudhury SS, Kakoty SD, Sarma UC, Webster P, Knight M. Association between maternal anaemia and pregnancy outcomes: a cohort study in Assam, India. BMJ Global Health. 2016;1(1):e000026.

22. Sangeeta VB, Pushpalatha S. Severe maternal anaemia and neonatal outcome. Sch J App Med Sci. 2014; 2(1C):303-9.

23. Kiyani AN, Khushdil A, Ehsan A. Perinatal factors leading to birth asphyxia among term newborns in a tertiary care hospital. Iranian J Paediatr. 2014;24(5):637.

24. Rani KU, Gupta J, Gupta R, Aggarwal KC. Maternal anaemia and its severity: an independent risk factor for preterm delivery and adverse neonatal outcome. Int J Reproduct, Contracep, Obstet Gynaecol. 2017 ;3(2):325-9.

25. Maka SS, Tondare SB, Tondare MB. Study of impact of anaemia on pregnancy. Int J Reproduct, Contracep, Obstet Gynaecol. 2017;6(11):4847-50.

Cite this article as: Miglani $\mathrm{U}$, Bhangadia $\mathrm{P}$, Kadam VK, Laul P. Anaemia in term pregnancy: influence on maternal and perinatal outcome and role of demographic factors. Int J Reprod Contracept Obstet Gynecol 2019;8:251-7. 